\title{
Single $3^{\circ}$ tapered fluted femoral stems demonstrate low subsidence at mid-term follow-up in severe bony deficiency
}

\author{
Albert W. T. Ngu, Fiachra E. Rowan, Alberto V. Carli, Fares S. Haddad \\ Department of Orthopaedic Surgery, University College London Hospital, London, UK \\ Contributions: (I) Conception and design: FS Haddad, A Carli; (II) Administrative support: AWT Ngu; (III) Provision of study materials or patients: \\ FS Haddad; (IV) Collection and assembly of data: AWT Ngu, A Carli; (V) Data analysis and interpretation: All authors; (VI) Manuscript writing: All \\ authors; (VII) Final approval of manuscript: All authors. \\ Correspondence to: Mr. Albert Wee Tun Ngu. Department of Orthopaedic Surgery, 250, Euston Road, London NW1 2PG, UK. \\ Email: albertngu87@gmail.com.
}

Background: Tapered femoral stems have become popular in revision total hip arthroplasty (rTHA).
Increasing the distal taper angle may mitigate subsidence. This study reports osseointegration of a new 3
degree distal taper revision stem at minimum 4 years post-operatively.
Methods: Indication for surgery, pre-operative bony deficiency and latest clinical, tribological and
radiological follow-up were analysed. Radiographs were assessed by two blinded observers for preoperative
femoral bone stock according to Paprosky, postoperative subsidence according to Callaghan and restoration
of femoral bone stock over time according to Kolstad. Stem integration was determined using the Rodriguez
classification.

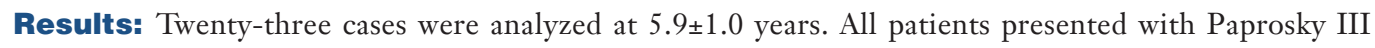
defects. All stems met the criteria for osseointegration. Spot welds occurred distal to the proximal modular junction and at the tip. Two femora with severe proximal femoral bone loss recovered bone stock by final follow-up but two demonstrated stress shielding. No intraoperative fractures occurred. One stem subsided early but remained stable and osseointegrated at final follow up. There were no stem failures due to taper corrosion or modular junctional failure.

Conclusions: This study reports good osseointegration and low subsidence with a novel fluted, 3-degree tapered femoral stem demonstrates at medium-term follow-up in cases with severe femoral bone deficiency.

Keywords: Revision hip arthroplasty; tapered stems; femoral bone loss; osseointegration

Submitted Aug 25, 2019. Accepted for publication Nov 05, 2019.

doi: $10.21037 /$ atm.2019.12.19

View this article at: http://dx.doi.org/10.21037/atm.2019.12.19

\section{Introduction}

Dealing with femoral bone loss remains a major challenge in revision total hip arthroplasty (rTHA). Severe femoral bone loss (Paprosky type III and IV) has been independently associated with inferior survivorship following revision surgery and has prompted investigation into optimal implant design for achieving stable fixation in the femoral isthmus or remaining diaphysis (1-3). Tapered titanium stems have gained popularity for revising primary THAs with moderate to severe proximal femoral bone loss. These stems are an attractive surgical option due to their reasonably straightforward surgical technique, use of titanium alloy that facilitates load transfer while minimizing stress shielding, and tapered geometry that achieves axial stability with little cortical contact required through the Wagner philosophy (4-7).

Novel tapered stem designs have developed in response to concerns for subsidence, but may themselves introduce new complications. The original Wagner design has been associated with a subsidence of $10 \mathrm{~mm}$ in up to $27 \%$ of cases, a finding attributed to component undersizing and the presence of 2-degree taper in the diaphyseal engaging 
segment $(8,9)$. In response, subsequent modular designs utilize increasingly tapered diaphyseal segments with taper angles up to $3.5^{\circ}$, a change that may theoretically diminish subsidence risk, but increase the risk of intraoperative fracture during implant impaction (10). Meanwhile, concerns with high rates of instability following tapered stem insertion have led the introduction of additional modular interfaces which, while facilitating the reproduction of offset and length, also bring concerns for fracture or corrosion at these interfaces. Almost all primary and revision stems with modular necks have been recalled $(11,12)$. Reports exist in the literature relating to modular body failures but recalls of modular body revision stems are not ubiquitous (13). Due to the uncertainty of the benefits of modular taper design changes, literature regarding the clinical and radiographic performance of these implants is critical $(10,12,14)$. The novel stem described in this series has undergone a Class II recall since January 2017 due to neck modularity and associated corrosion behaviour demonstrated in similar designs from other manufacturers.

The aim of this study was to assess performance of a novel modular tapered fluted stem. In particular we wanted to determine incidence of stem osseointegration and rate of revision due to modular neck corrosion. Within the current study, we report mid-term follow-up of the clinical, tribological and radiographic findings of patients with significant femoral bone loss that received a novel modular tapered stem consisting of a single $3^{\circ}$ diaphyseal taper and modularity involving both the proximal body and femoral neck.

\section{Methods}

Institutional ethics board approval was attained. Prospectively gathered data pertaining to a continuous series of patients that had a single $3^{\circ}$ tapered fluted modular revision system (Redapt, Smith \& Nephew, London, UK) implanted during revision THA were retrospectively analysed. Only patients with at least 4 years' follow up were included therefore 23 cases between May 2011 and September 2014 are included for final analysis. The indication for using this femoral stem was femoral component revision with or without acetabular revision in the presence of poor proximal femoral bone stock consistent with a Paprovsky III defect (1).

\section{Patients}

Patient age, gender, body mass index (BMI) and reason for revision were recorded. Surgery was performed using a posterolateral approach. Stem diameter and length, modular body dimension, modular neck offset and head diameter and length were recorded. Pre-existing femoral components were removed with the aid of a trochanteric osteotomy were necessary. Acetabular revision to a multihole porous titanium modular acetabular component was performed where indicated. Patients were permitted to toetouch weight-bear for 6 weeks and progressed to full weight bearing by 3 months. Clinical score (Harris Hip Score; Oxford Hip Score) at most recent follow-up was recorded. Implant failure was defined as the need to undergo a subsequent femoral component revision and, if this did occur, the length of implantation, reason for subsequent revision and any perioperative complication were noted.

\section{Radiographic analysis}

All radiographs were analysed by two observers who were blinded to patient data and any discrepancies were resolved through a subsequent consensus meeting. Preoperative femoral bone stock was assessed using the Paprosky classification. Implant subsidence was determined according to the system published by Callaghan (14). When the greater trochanter could not be used as a fixed bony landmark, the lesser trochanter was used as an alternative landmark as previously performed by Malchau (15). When neither trochanters were easily identified, a femoral landmark consistent on all studied films within the same patient was utilized. All radiographs were calibrated using a radio-opaque marker of known size or from the known size of the femoral head. Restoration of femoral bone stock was classified according to the system described by Kolstad as "no bone regeneration", "possible regeneration" and "definite bone formation" (16). Implant osseointegration was defined using a modified version of the Engh classification described by Rodriguez (17). The definition of osseointegration used was: "an implant with minimal or no radio-opaque line formation at the grit-blasted surface of the "distal segment" (and not the entire implant) with or without presence of endosteal spot welds and no subsidence beyond the initial 6 weeks of full weight bearing". Accordingly, only "stable fibrous ingrowth" or "unstable implant" were used to describe the status of implant stability. Spot welds were defined as new bone bridging the endosteum and porous surface of the implant and were classified according to the five types described specifically for modular tapered stems by Rodriguez (17). Stress 
shielding was defined as an area of diminished radiodensity between two areas of spot welds along the distal stem segment and was documented according to their location in relation to the Gruen zone on the anteroposterior view (18).

\section{Statistical analysis}

Summary statistics were calculated for patient variables and radiographic factors. Cohen's kappa statistic was calculated for identification of spot welds according to the Rodriguez classification. Statistical analysis was performed using the statistical SPSS Version 23.0 software (SPSS Inc., Chicago, IL, USA).

\section{Results}

\section{Clinical outcome and revision surgery}

There were 13 female and 10 male patients with a mean age

Table 1 Patients

\begin{tabular}{lc}
\hline Characteristic & Outcome \\
\hline Follow-up (mean $\pm \mathrm{SD}$, years) & $5.9 \pm 1.0$ \\
Age (mean $\pm \mathrm{SD}$, years) & $76.9 \pm 5.7$ \\
Sex (M:F) & $13: 10$ \\
BMI (mean $\left.\pm \mathrm{SD}, \mathrm{kg} / \mathrm{m}^{2}\right)$ & $28.2 \pm 8.2$ \\
Femoral deficiency (Paprosky), $\mathrm{n}$ & 11 \\
IIIA & 12 \\
IIIB & \\
Indication for revision, $\mathrm{n}$ & 13 \\
Aseptic loosening & 7 \\
Prosthetic joint infection & 2 \\
Instability & 1 \\
Stem fracture & \\
\hline
\end{tabular}

of $76.9 \pm 5.7$ years and mean BMI of $28.2 \pm 8.2 \mathrm{~kg} / \mathrm{m}^{2}$ at time of surgery. Preoperative femoral bone stock was consistent with Paprosky IIIA in rating for 11 hips and Paprosky IIIB for 12 hips. Surgery was most commonly performed for aseptic femoral loosening (Table 1). Distal stem diameter was most frequently $17 \mathrm{~mm}$ and modular body was frequently small. Ceramicised metal alloy heads were used in all cases and were most frequently $32 \mathrm{~mm}$ in diameter. Standard offset necks were used in eight cases. There were no intra-operative femoral fractures either during femoral preparation or upon implant impaction. Post-operative Harris hip score and Oxford hip score at final follow-up was $70.7 \pm 18.6$ and $37.6 \pm 7.4$ respectively. There were no revisions for stem failure. One patient underwent revision surgery for acetabular component loosening 2.7 years postoperatively and another patient underwent revision of acetabular liner and head exchange for instability 3.5 years post-operatively. Neither patient required stem revision. Serum cobalt and chromium ion levels were $6.0 \pm 5.3$ and $10.5 \pm 5.5 \mathrm{nmol} / \mathrm{L}$ respectively $(0.35 \pm 0.3$ and $0.54 \pm 0.2 \mathrm{ppm})$ at latest clinical review.

\section{Osseointegration, subsidence and bone remodelling}

At final follow-up, all 23 stems were determined to be osseointegrated using the Rodriguez classification. Distal radial welds were the most common finding among osseointegrated stems (type 4: 19 of 23; 82.6\%) and were associated with distal junctional welds (type $2 \mathrm{~B}$ : 10 of 23 ; $43.5 \%$ ) and distal anterior welds (type $3: 10$ of $23 ; 43.5 \%$ ) (Table 2). The remaining stems demonstrated spanning junctional welds (type 2A). One stem demonstrated subsidence greater than $5 \mathrm{~mm}$ that remained stable with final follow-up radiographs showing Type 4 osseointegration. Stress shielding was evident in Gruen zones 7 and 8 in two cases. Proximal bone remodelling was present in two cases at Gruen zones 6 and 7. The calculated Cohen's kappa statistic for the presence of spot welds was 0.67 , suggesting a substantial agreement among observers.

Table 2 Osseointegration

\begin{tabular}{lcccccccc}
\hline \multirow{2}{*}{ Femoral deficiency } & \multirow{N}{*}{$\mathrm{N}$} & \multicolumn{9}{c}{ Spot welds } & \multicolumn{2}{c}{ Subsidence >5 mm } \\
\cline { 3 - 8 } & & Type 1 & Type 2A & Type 2B & Type 3 & Type 4 & Type 5 \\
\hline IIIA & 11 & 0 & 2 & 4 & 5 & 9 & 1 & 1 \\
IIIB & 12 & 0 & 1 & 6 & 5 & 10 & 1 & 0 \\
\hline
\end{tabular}




\section{Discussion}

The main finding of this patient series is that a novel fluted, 3-degree tapered femoral stem demonstrates good osseointegration and low subsidence at medium-term follow-up in cases with severe femoral bone deficiency. We also report no revisions due to corrosion in a previously recalled modular neck stem or modular body junctional failures in a previously recalled modular neck stem. We consider that the single case of subsidence of approximately $4 \mathrm{~mm}$ in one stem was due to undersizing of the distal component. There is evidence that undersizing is associated with a higher short-term periprosthetic fracture risk and long-term aseptic loosening risk (19,20).

A lingering concern with modular, tapered stems is the possibility of subsidence within the short term, with Böhm, Rodriguez and Park all reporting $>10 \mathrm{~mm}$ subsidence rates in over $5 \%$ of cases $(17,21,22)$. Yet while femoral bone stock and surgical technique may contribute to subsidence risk, a relatively unexplored contribution is implant design, specifically the distal taper angle and flute configuration. In a biomechanical study of ten custom-designed modular, tapered stems, Pierson found that increasing taper angle and broader splines were the two implant features that contributed significantly to axial stability (23). Since the stem investigated in the current study has an increased taper angle compared to the three previously cited clinical studies and a novel flute arrangement consisting of tall 'major' flutes and broad 'minor' flutes, these features could contribute to the minimal subsidence and high implant survival reported. A prospective clinical comparison of several modular tapered stem designs is evidently needed to determine if such designs impact long-term survival.

We acknowledge several limitations for this study. The main limitation is that the senior surgeon is a design surgeon for the implant being evaluated. Furthermore, the device has been recalled and although the distal geometry has been continued by the manufacturers in a monoblock version of the stem, this series cannot be used as a surrogate for success of the non-modular device. Finally, we present low numbers. The main reason to report such a low volume series was to only include those patients with at least 4 years follow-up and an average of almost 6 years results. Recall of the device prompted us to test serum cobalt and chromium ion levels and we were pleased to show no corrosion related failures.

In conclusion, we report good results of a tapered distal stem geometry but acknowledge that independent observers' results of their experience using the stem and later monoblock stems with the same geometry and fluting are required in greater numbers before the true mid-term results of this design are known.

\section{Acknowledgments}

None.

\section{Footnote}

Conflicts of Interest: The authors have no conflicts of interest to declare.

Etbical Statement: The authors are accountable for all aspects of the work in ensuring that questions related to the accuracy or integrity of any part of the work are appropriately investigated and resolved.

\section{References}

1. Della Valle CJ, Paprosky WG. The femur in revision total hip arthroplasty evaluation and classification. Clin Orthop Relat Res 2004;(420):55.

2. Bozic KJ, Katz P, Cisternas M, et al. Hospital resource utilization for primary and revision total hip arthroplasty. J Bone Joint Surg Am 2005;87:570.

3. Patel PD, Klika AK, Murray TG, et al. Influence of technique with distally fixed modular stems in revision total hip arthroplasty. J Arthroplasty 2010;25:926.

4. Wixson RL, Stulberg SD, Van Flandern GJ, et al. Maintenance of proximal bone mass with an uncemented femoral stem analysis with dual-energy $x$-ray absorptiometry. J Arthroplasty 1997;12:365.

5. Kiratli BJ, Heiner JP, McBeath AA, et al. Determination of bonemineral density by dual $x$-ray absorptiometry in patients with uncemented total hip arthroplasty. J Orthop Res 1992;10:836.

6. Tangsataporn S, Safir OA, Vincent AD, et al. Risk Factors for Subsidence of a Modular Tapered Femoral Stem Used for Revision Total Hip Arthroplasty. J Arthroplasty 2015;30:1030-4

7. Wagner H, Wagner M. Cone prosthesis for the hip joint. Arch Orthop Trauma Surg 2000;120:88.

8. Sandiford NA, Duncan CP, Garbuz DS, et al. Tapered, fluted titanium stems in revision total hip arthroplasty: role and results in contemporary practice. Instr Course Lect 2015;64:359-66. 
9. Isacson J, Stark A, Wallensten R. The Wagner revision prosthesis consistently restores femoral bone structure. Int Orthop 2000;24:139-42.

10. Swanson TV. Tapered, fluted femoral fixation. In: Brown TE, Cui Q, Mihalko WM, et al. editors. Arthritis and Arthroplasty. Philadelphia, PA: Elsevier, 2009:354-62.

11. Brown NM, Tetreault M, Cipriano CA, et al. Modular tapered implants for severe femoral bone loss in THA: reliable osseointegration but frequent complications. Clin Orthop Relat Res 2015;473:555-60.

12. Lakstein D, Eliaz N, Levi O, et al. Fracture of cementless femoral stems at the mid-stem junction in modular revision hip arthroplasty systems. J Bone Joint Surg Am 2011;93:57-65.

13. Cooper HJ, Urban RM, Wixson RL, et al. Adverse local tissue reaction arising from corrosion at the femoral neckbody junction in a dual-taper stem with a cobalt-chromium modular neck. J Bone Joint Surg Am 2013;95:865-72.

14. Callaghan JJ, Salvati EA, Pellicci PM, et al. Results of revision for mechanical failure after cemented total hip replacement, 1979 to 1982. A two to five year follow-up. J Bone Joint Surg Am 1985;67:1074.

15. Malchau H, Karrholm J, Wang YX, et al. Accuracy of migration analysis in hip arthroplasty: digitalized and conventional radiography, compared to radiostereometry in 51 patients. Acta Orthop Scand 1995;66:418.

16. Kolstad K, Adalberth G, Mallmin H, et al. The Wagner

Cite this article as: Ngu AWT, Rowan FE, Carli AV, Haddad FS. Single $3^{\circ}$ tapered fluted femoral stems demonstrate low subsidence at mid-term follow-up in severe bony deficiency. Ann Transl Med 2019;7(23):725. doi: 10.21037/atm.2019.12.19 revision stem for severe osteolysis: 31 hips followed for 1.5-5 years. Acta Orthop Scand 1996;67:541.

17. Rodriguez JA, Deshmukh AJ, Klauser WU, et al. Patterns of osseointegration and remodeling in femoral revision with bone loss using modular, tapered, fluted, titanium stems. J Arthroplasty 2011;26:1409-17.e1.

18. Gruen TA, McNeice GM, Amstutz HC. "Modes of failure" of cemented stem-type femoral components: a radiographic analysis of loosening. Clin Orthop Relat Res 1979;141:17.

19. Van Houwelingen AP, Duncan CP, Masri BA, et al. High survival of modular tapered stems for proximal femoral bone defects at 5 to 10 years followup. Clin Orthop Relat Res 2013;471:454-62.

20. Aldinger PR, Jung AW, Pritsch $M$, et al. Uncemented gritblasted straight tapered titanium stems in patients younger than fifty-five years of age. Fifteen to twenty-year results. J Bone Joint Surg Am 2009;91:1432-9.

21. Böhm P, Bischel O. Femoral revision with the Wagner SL revision stem. J Bone Joint Surg 2001;83:1023.

22. Park MS, Lee JH, Park JH, et al. A distal fluted, proximal modular femoral prosthesis in revision hip arthroplasty. J Arthroplasty 2010;25:932.

23. Pierson JL, Small SR, Rodriguez JA, et al. The Effect of Taper Angle and Spline Geometry on the Initial Stability of Tapered, Splined Modular Titanium Stems. J Arthroplasty 2015;30:1254-9. 